\title{
A Study of Factors Affecting Customer Adoption of 3G Service in China
}

\author{
Yongbing Jiao ${ }^{1}$ Jian Yang ${ }^{1}$ Shanling Xu ${ }^{1}$ \\ ${ }^{1}$ School of Economics \& Management, Ningbo University of Technology, Ningbo, China \\ Corresponding author: Yongbing Jiao Email: robynjoy@outlook.com
}

\begin{abstract}
Though Chinese telecom operators has provided $3 \mathrm{G}$ service to their customers for more than three years, the study of the factors affecting customer adoption of $3 \mathrm{G}$ service in China has not been conducted yet by scholars. The purpose of this study is to fill this void. Through the investigation of the samples of 413 customers of 3 Chinese telecom operators and the data analysis run by AMOS 18.0 and SPSS 18.0, we found that perceived value has a positive impact on customer adoption, that perceived enjoyment and perceived service quality have a positive impact on perceived value respectively, and that perceived safety and perceived price has a negative impact on perceived value respectively. However, we found unexpectedly that industry standard has no impact on perceived value.
\end{abstract}

Keywords: $3 \mathrm{G}$ service, adoption, factors

\section{Introduction}

It has been more than three years since the three Chinese telecom operators, China Mobile, China Unicom and China Telecom, provided their third generation (3G) service to their customers. 3G service will bring a lot of profit to the three Chinese telecom operators, so they have been competing severely against one another in order to get the most customer share. By the end of June, 2013, the number of $3 \mathrm{G}$ service customers in China is more than 3 hundred million, in which the number of customers of China Mobile is more than 1.3 hundred million, the number of customers of China Unicom is nearly 1 hundred million, and the number of customers of China Telecom is almost 0.9 hundred million.

Meanwhile, it seems that the study on customer adoption of $3 \mathrm{G}$ service in China has been far lagging behind. All most no literature can be found to be involved with $3 \mathrm{G}$ service adoption in Chinese market. The purposes of this study is to fill this void.

\section{Literature Review}

The research on $3 \mathrm{G}$ service adoption can be conducted in accordance with the information technology theories such as Theory of Technology Acceptance (TAM), Innovation Diffusion Theory (IDT), Unified Theory of Acceptance and Use of Technology (UTAUT), etc.

Based on TAM, Adler found that the most important factor impacting $3 \mathrm{G}$ service adoption is speed [1], Pagani verified that perceived value has a positive impact on $3 \mathrm{G}$ service adoption [2], Phuangthong \& Malisawan proved that perceived enjoyment impacts $3 \mathrm{G}$ service acceptance positively [3], Cocosila et al. concluded that perceived usefulness is the most important factor influencing 3G service adoption [4], and Karjaluoto revealed price and industry standard are necessary factors impacting customers adopting $3 \mathrm{G}$ service [5]. 
According to IDT, Lee et al.'s findings demonstrated the factors influencing $3 \mathrm{G}$ service adoption are telecom technology, policy, industry, and demography [6], Pagani articulated that price is the main factor which impacts customers adopting 3G service [7].

In light of UTAUT, Yu et al. argued effort expectation negatively impacts $3 \mathrm{G}$ service adoption, whereas facilitating conditions, performance expectation and social expectation positively impact $3 \mathrm{G}$ service adoption [8].

The aforesaid investigated the factors influencing customer adoption of $3 \mathrm{G}$ service from various perspectives. Yet no scholars can be found conduct the research on customers adopting 3G service in Chinese market. The Chinese $3 \mathrm{G}$ market has its uniqueness because each of the 3 Chinese telecom operators has its own industry standard. Therefore, one of our aims in this study is to testify whether industry standard will impact $3 \mathrm{G}$ service adoption.

\section{Research Model And Hypotheses}

\subsection{Research Model}

Based upon the existing literature we built the research model (Fig. 1).

As is illustrated in Fig.1, the research model includes one endogenous variable (adoption), five exogenous variables (perceived risk, perceived enjoyment, perceived service quality, perceived price, and industry standard), and one mediating

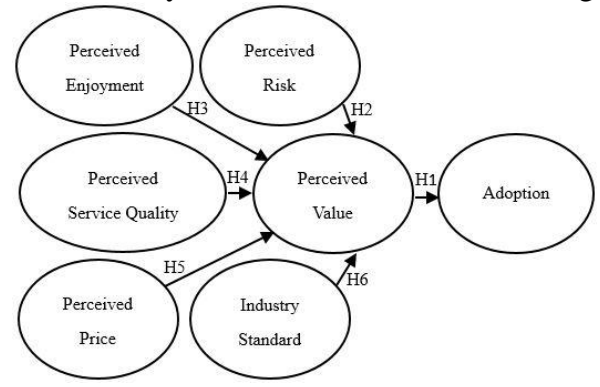

Fig. 1: The research model variable (perceived value) in $3 \mathrm{G}$ service environment.

\subsection{Hypotheses}

We argue that in the circumstances of $3 \mathrm{G}$ service, customers' perceived value will affect customer adoption positively. High perceived value means high perceived benefit and low perceived sacrifice to customers. Customers will choose to adopt $3 \mathrm{G}$ service if they perceive high value of it, and vice versa [9]. Cronin et al.'s research findings demonstrated that perceived value has a positive impact on customers' behavioral intentions [10]. Therefore we can infer as follows.

H1: Perceived Value has a positive effect on Customer Adoption.

Perceived risk refers to an unexpected unhappy outcome possibly resulted from the buying behavior that customers will adopt. Customers will perceive risk when feeling that their buying target can impossibly be reached from their buying experiences [11]. In e-business, perceived risk can be referred to a transactional risk possibly faced by customers when trading through electronic channels [12]. A lot of research verified that perceived risk is the main obstacle to customers adopting internet service [12]. Thus, we can infer that perceived risk will reduce customers' perceived value.

$\mathrm{H} 2$ : Perceived Risk has a negative effect on Perceived Value.

Perceived enjoyment refers to the playfulness degree that users feel by themselves while using computers [13]. Teo et al. found that perceived enjoyment will impact users' adoption intention positively [14] as users can experience perceived value when using computers. Moon \& Kim found that perceived enjoyment will impact users' adoption intention positively [15] as users can experience perceived value when using internet. Hence in the context of $3 \mathrm{G}$ service, we can infer as follows. 
H3: Perceived Enjoyment has a positive impact on Perceived Value.

Perceived service quality refers to customers' subjective evaluation of the overall service quality [9]. In the $3 G$ service conditions, customers will perceive not only reliability, accessibility, usability of the network but also service quality of different kinds of software and hardware. If they perceive high quality in $3 \mathrm{G}$ service, customers will be prone to adopt it because they can perceive high value of it. Therefore we can give the following inference.

H4: Perceived Service Quality has a positive impact on Perceived Value.

Perceived price is the comparison between target price and reference price [16]. Perceived price is also referred to a customer's subjective perception of the target price of a product or a service [17]. Teas \& Agarwal verified that there is a negative relationship between perceived price and perceived value [18]. Thus in the circumstances of $3 \mathrm{G}$ service, we can infer as follows.

H5: Perceived Price has a negative impact on Perceived Value.

There exists different standards such as WCDMA, CDMA2000, FOMA, TDSCDMA, etc. in 3G service in the world nowadays. WCDMA, CDMA2000 and TD-SCDMA have been the standards adopted separately by China Unicom, China Telecom and China Mobile. In 3G service context, industry standard impacts the effectiveness and efficiency of the mobile network service, thus it further impacts customers' adoption willingness [7]. Customers intend to accept 3G service with effective and efficient standard as they want to experience high perceived value. And so we can infer as follows.

H6: Industry Standard has a positive impact on Perceived Value.

\section{Research Methodology}

\subsection{Operational Variable Measure- ment and Questionnaire Design}

We design the questionnaire according to Likert 7-point Scale, ranging from "Strongly Disagree" to "Strongly Agree". We firstly designed the questions on the basis of the existing literatures which have been proved to have good validity and reliability. And then we revised and modified the questions in the light of the suggestions and opinions of some experts from the research fields of internet marketing and e-commerce. The scale of adoption is designed in line with the research by Davis [13], the scale of perceived value and perceived service quality are developed in the light of the study by Zeithaml [9], the scale of perceived risk is developed according to the research by Park et al. [12], the scale of perceived enjoyment is designed on the basis of the research by Moon \& Kim [15], the scale of perceived price is designed in the light of the research by Jacoby \& Olson [17], and the scale of industry standard is developed based on the research by Karjaluoto [5].

\subsection{Data Collection and Sample Characteristics}

The respondents are selected from the customers of China Mobile, China Unicom and China Telecom, which are located in Ningbo. Data were collected by means of field survey which was conducted from March to July, 2012. 800 questionnaires were sent and 500 ones were collected, thus the collection rate is $62.5 \%$. Then according to consistency test, 87 invalid questionnaires were deleted, and so the valid ones are 413 , the response rate is $51.6 \%$.

With regard to the characteristics of the respondents, the male is about $57.2 \%$, and the female is about $42.8 \%$; the persons from 18 to 45 years of age occupy $83 \%$. 
Tab. 1: Measurement model test

\begin{tabular}{|c|c|c|c|c|c|c|c|c|c|}
\hline $\begin{array}{l}\text { Varia- } \\
\text { ble }\end{array}$ & Item & GFI & $\overline{\text { AGFI }}$ & RMR & RMSEA & $\overline{C F I}$ & $\begin{array}{l}\text { Cronb- } \\
\text { ach's } \alpha\end{array}$ & FL & SMC \\
\hline \multirow{3}{*}{ AD } & AD1 & \multirow{3}{*}{.924} & \multirow{3}{*}{.921} & \multirow{3}{*}{.027 } & \multirow{3}{*}{.006. } & \multirow{3}{*}{943} & \multirow{3}{*}{.82} & .707 & .654 \\
\hline & AD2 & & & & & & & .702 & .701 \\
\hline & AD3 & & & & & & & .704 & .621 \\
\hline \multirow{4}{*}{ PV } & PV1 & \multirow{4}{*}{.976} & \multirow{4}{*}{.931} & \multirow{4}{*}{.014} & \multirow{4}{*}{.004 } & \multirow{4}{*}{.976} & \multirow{4}{*}{.81} & .731 & .724 \\
\hline & PV2 & & & & & & & .711 & .698 \\
\hline & PV3 & & & & & & & .737 & .675 \\
\hline & PV4 & & & & & & & .704 & .661 \\
\hline \multirow{3}{*}{ PR } & PR1 & \multirow{3}{*}{.922 } & \multirow{3}{*}{.926 } & \multirow{3}{*}{.016 } & \multirow{3}{*}{.003 } & \multirow{3}{*}{.982 } & \multirow{3}{*}{.81} & .813 & .594 \\
\hline & PR2 & & & & & & & .809 & .597 \\
\hline & PR3 & & & & & & & .707 & .623 \\
\hline \multirow{3}{*}{$\mathbf{P E}$} & PE1 & \multirow{3}{*}{.991} & \multirow{3}{*}{.994} & \multirow{3}{*}{.017} & \multirow{3}{*}{.001} & \multirow{3}{*}{.998} & \multirow{3}{*}{.87} & .725 & .811 \\
\hline & PE2 & & & & & & & .577 & .581 \\
\hline & PE3 & & & & & & & .758 & .676 \\
\hline \multirow{3}{*}{ PSQ } & PSQ1 & \multirow{3}{*}{.946} & \multirow{3}{*}{.899} & \multirow{3}{*}{.006 } & \multirow{3}{*}{.009} & & & .709 & .833 \\
\hline & PSQ2 & & & & & .897 & .94 & .821 & .729 \\
\hline & PSQ3 & & & & & & & .790 & .642 \\
\hline & PP1 & & & & & & & .767 & .823 \\
\hline PP & PP2 & .965 & .977 & .003 & .006 & .928 & .97 & .871 & .714 \\
\hline & PP3 & & & & & & & .760 & .596 \\
\hline & IS1 & & & & & & & .783 & .613 \\
\hline IS & IS2 & .964 & .937 & .015 & .003 & .968 & .83 & .729 & .622 \\
\hline & IS3 & & & & & & & .802 & .702 \\
\hline
\end{tabular}

Notes: Factor Loading is significant at $\mathrm{p}=0.001$ level. $\mathrm{AD}=$ Adoption, $\mathrm{PV}=$ Perceived Value, $\mathrm{PR}=$ Perceived Risk, $\mathrm{PE}=$ Perceived Enjoyment, PSQ=Perceived Service Q uality, PP=Perceived Price, IS=Ind ustry Standard

The respondents from white collars in companies, from government agencies, from hospitals, and from the educational and research departments are $79 \%$. The respondents whose monthly income are between 2001 and 7000RMB occupy $74 \%$. The persons who have the junior college level or above are $87 \%$. The respondents who are single occupy $72 \%$ and those who are married occupy $28 \%$.

The respondents from China Mobile occupy $38 \%$, the respondents from China Unicom occupy 33\%, and the respondents from China Telecom occupy $29 \%$.

\section{Data Analysis}

\subsection{Measurement Model Test}

With the help of AMOS 18.0 and SPSS 18.0 , we conducted the reliability and validity test of measurement model. As we can see from Table 1, the value of Cronbach's a in every variable is equal to or above 0.80 , and the value of SMC (Squared Multiple Correlations) in every item of each variable is equal to or above 0.50 , which mean all the variables have a higher internal consistency reliability. The FL (Standard Factor Loading) value of each item in every variable is equal or over 0.70 under the condition of $p=0.001$, meaning each variable has a good validity. The values of GFI (Goodness of Fit Index), AGFI (Adjust Goodness of Fit Index) and CFI (Comparative Fit Index) of all the variables are above 0.90 or nearly up to 0.90 , and the values of RMR (Root Means square Residual) and RMSEA (Root Mean Square Error of Approximation) of all the variables are below 0.05 , therefore all the variables have satisfying goodness of fit and validity.

\subsection{Structural Model Test}

The structural model test is illustrated in

Table 2 and figure 2 . 
As we can see from Table 2, the value of CMIN/DF (Ratio chi-square with Degrees of Freedom) is 2.213 (between 2.0 and 5.0), the values of GFI (Goodness of Fit Index), AGFI (Adjust Goodness of Fit Index), CFI (Comparative Fit Index), NFI (Normed Fit Index) and IFI (Incremental Fit Index) are above 0.90, the value of RMR (Root Means square Residual) is below 1.0, and the value of RMSEA (Root Mean Square Error of Approximation) is below 0.05. And so the overall structural model has a good fit.

Tab. 2: Structural Model Test

\begin{tabular}{|l|l|l|l|l|}
\hline Index & CMIN/DF & GFI & AGFI & CFI \\
\hline Result & 2.213 & .927 & .919 & .931 \\
\hline Index & NFI & IFI & RMR & RMSEA \\
\hline Result & .928 & .922 & .102 & .007 \\
\hline
\end{tabular}

Judging from the standard road coefficient of the structural equation model, we can evaluate whether or not the hypotheses are acceptable. As is shown in figure 2 , under the condition of significance level at $\rho \leq 0.001$, the standard road coefficient of hypothesis 2 is -0.29 , so hypothesis 2 is acceptable; the standard road coefficient of hypothesis 3 is 0.32 , so hypothesis 3 is also acceptable. Under the condition of significance level at $\rho \leq 0.01$, the standard road coefficient of hypothesis 1 is 0.39 , so hypothesis 1 can be accepted; the standard road coefficient of hypothesis 4 is 0.33 , so hypothesis 4 is acceptable; the standard road coefficient of hypothesis 5 is -0.26 , so hypothesis 5 is also acceptable.

However, under the condition of significance level at $\rho \leqslant 0.01$, the standard

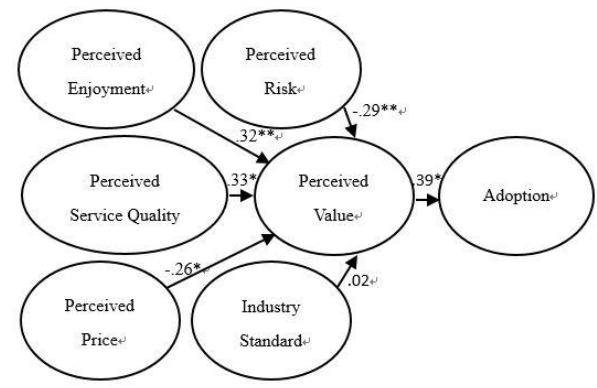

Notes: **represents the standard road coefficient is significant a $\rho \leq 0.001$ level, *represents the standard road coefficient is significant at $\rho \leq 0.01$ level.

Fig. 2: The standard road coefficient of the model road coefficient of hypothesis 6 is 0.02 , and so hypothesis 6 is unacceptable.

\section{Conclusions}

The contribution of the research is to construct a model describing customer adoption of $3 \mathrm{G}$ service and its factors in China. The model demonstrated adequate fit with the data; all the other causal relationships in this model were found to be significant except that the relationship between industry standard and perceived value was testified to be insignificant.

The findings of this study suggests the following managerial implications for the 3 Chinese telecom operators to develop $3 \mathrm{G}$ service. First, the 3 operators should make their great effort to improve customers' perceived value so as to attract much more customers to adopt their $3 \mathrm{G}$ service. Second, the 3 operators should endeavor to reduce the customers' perceived risk and perceived price in order to raise customers' perceived value. Third, the 3 operators have to improve customers' perceived service quality and perceived enjoyment to enhance customers' perceived value. Last, it is verified that industry standard has no impact on customers' perceived value, which means that customers don't care much about the technical differences among the 3 operators. Therefore, the 3 operators should lay their emphasis on how to improve customers' perceived value so as to get more customer shares in Chinese 3G service market.

Acknowledgment: (i) This study is funded by the Humanities and Social Sciences Fund of Ministry of Education (grant \#, 13YJA630038), China. (ii) This study is funded by the Special Program of the Academic Discipline of Humanities and Social Sciences Rehabilitation Foundation, Ningbo University of Technology, China. (iii) The author 
gratefully acknowledges the support of K.

C. Wong Education Foundation.

\section{References}

[1] T.R. Adler, "Member Trust in Teams: A Synthesized Analysis of Contract Negotiation in Outsourcing IT Work," Jour. Of Computer Information Systems, 44(2), pp. 6-16, 2004.

[2] M. Pagani, "Determinants of Adoption of Third Generation Mobile Multimedia Services," Jour. Of Interactive Marketing, 18(3), pp.46-59, 2004.

[3] D. Phuangthong and S. Malisawan, "A Study of Behavioral Intention for 3G Mobile Internet Technology: Preliminary Research on Mobile Learning," Proc. Of the Second International Conference on eLearning for Knowledge-Based Society, pp. 17.117.7, 2005.

[4] M. Cocosila, O. Turel, N. Archer, and Y. Yuan, "Perceived Health Risks of 3G Cell Phones: Do Users Care?" Communications of the ACM, 50(6), pp. 89-92, 2007.

[5] H. Karjaluoto, "An Investigation of Third Generation (3G) Mobile Technologies and Services," Contemporary Management Research, 2(2), pp. 91-1042006.

[6] S. Lee, M. Sylvia, and H. Kim, "The Deployment of Third-Generation Mobile Services: A Multinational Analysis of Contributing Factors," Working paper, 2009.

[7] M. Pagani, "A Vicarious Innovativeness Scale for 3G Mobile Services: Integrating the Domain Specific Innovativeness Scale with Psychological and Rational Indicators," Technology Analysis \& Strategic Management, 19(6), pp. 709-728, 2007.

[8] Y. Wu, Y. Tao, and P. Yang, "Using UTAUT to explore the behavior of 3G mobile communication users," Working Paper, 2010.
[9] V. A. Zeithaml, "Consumer Perceptions of Price, Quality, and Value: A Means-End Model and Synthesis of Evidence," Journal of Marketing, 52(3), pp. 2-22, 1988.

[10] J. Cronin, M.K. Brady, and G.T. Hult, "Assessing the Effects of Quality, Value, and Customer Satisfaction on Behavioral Intentions in Service Environments," Jour. Of Retailing, 76(2), pp. 193-218. , 2000.

[11] D. F. Cox, "Risk Taking and Information Handling in Consumer Behavior," Boston: Harvard University, 1967.

[12] J. Park, D .Lee, and J.Ahn, "Risk-focused e-commerce adoption model: a cross-country study," Jour. Of Global Information Technology Management, 7(2), pp. 6-30, 2004.

[13] F.D. Davis, "Perceived usefulness, perceived ease of use, and user acceptance of information technology," MIS Quarterly, 9, pp. 319-340, 1989.

[14] T.S.H. Teo, V.K.G. Lim, and R.Y.C. Lai, "Intrinsic and Extrinsic Motivation in Internet Usage," Omega, 27(1), pp. 25-37, 1999.

[15] J. W. Moon, and Y. G. Kim, "Extending the TAM for a worldwide-web context," Information and Management, 38(4), pp. 217-230, 2001.

[16] R.H. Thaler, "Mental accounting and consumer choice," Marketing Science, 4, pp. 199-214, 1985.

[17] J. Jacoby and J.C. Olson, "Consumer response to price: an attitudinal information processing perspective," Moving Ahead in Attitude Research, pp. 73-86, 1977.

[18] R.K. Teas, and S. Agarwal, "The effects of extrinsic product cues on consumers' perceptions of quality, sacrifice, and value," Jour. Of the Academy of Marketing Science, 28(2), pp. 278-290, 2000. 